\begin{tabular}{|l|l|}
\hline $\begin{array}{l}\text { Postprint } \\
\text { Version }\end{array}$ & 1.0 \\
\hline $\begin{array}{l}\text { Journal website } \\
\text { Pubmed link }\end{array}$ & $\underline{\mathrm{http}: / / \mathrm{dx} . d 0 i .0 r g / \text { doi:10.1016/S0738-3991(99)00003-8 }}$ \\
\hline DOI & $\underline{10.1016 / \mathrm{W} 0738 \text {-3991(99)00003-8 }}$ \\
\hline
\end{tabular}

This is a NIVEL certified Post Print, more info at http://www.nivel.eu

\title{
Educating patient educators: enhancing instructional effectiveness in physical therapy for low back pain patients
}

\author{
Jan J. Kerssen, Emmy M. Sluijs, Peter F. M. VerhaAk, HanneKe J. KNiBbe AND IRMA
} M. J. HERMANS

Netherlands Institute of Primary Health Care, Utrecht, The, Netherlands

\section{ABSTRACT}

The objective of this research project was to study the effectiveness of a training program for the enhancement of patient education skills in physical therapy. In this paper the improvement of five of these skills is tested. These skills are aimed at a better monitoring of adherence problems during the treatment and at enhancing self-efficacy of the patient after treatment. In order to test the effectiveness of the program, complete treatments of 19 physiotherapists have been assessed before (1142 sessions, 130 patients) and after (775 sessions, 88 patients) the training program. Information on the instructions and solutions given to the patients was obtained with a registration form, completed after each session by the physiotherapist. The patient's perception of the effectiveness and feasibility of instructions was obtained from questionnaires, completed by the patient on three occasions. After the training only a minority of the trained skills appeared to be improved. All in all, the training program was not very effective. More effort is needed to develop training programs aimed at promoting patients' self-efficacy as well as measurement instruments to assess the effects of such programs.

\section{INTRODUCTION}

Back pain is one of the most frequent reasons for visiting a general practitioner or physical therapist [1, 2 and 3]. In the Netherlands, $22 \%$ of the patients referred by general practitioners for physical therapy have back pain [4]. In the USA, patients with low back pain represent $25 \%$ of all discharges from physical therapy practices [5]. The central physiotherapeutic intervention in the treatment of back pain patients is exercise therapy [6 and 7]. One of the main elements of exercise therapy is the education and instruction of patients about anatomy, the natural history of disorders of the back, the principles underlying posture, taking care of the back in daily activities, and pursuing a healthy lifestyle [8].

Almost all treatment sessions include educational activities [9 and 10]. In general, they relate 
to pain relief, recovery of functions, and prevention of recurrence [11]. Patient education is "a planned learning experience using a combination of methods such as teaching, counseling and behavior modification techniques which influence patients' knowledge and health behaviour" [12]. The aim is to influence patients' knowledge and health behaviour. Low back pain patients are often well aware of the principles of prevention, but they require advice on how to apply this knowledge in their daily lives, at work and at home [13]. Physiotherapists should play a role in this respect, but their efforts in patient education are often not fully effective [14, 15 and 16]. This may largely be a result of the lack of teaching offered in the vocational training of medical students and other health professional trainees [14]. Physiotherapists have had hardly any formal training in employing skills known to enhance instructional effectiveness [17, 18 and 19]. As a result physiotherapists encounter many problems when they try to educate their patients [20 and 21]. These problems might be responsible for one of the large problems in health care, the problem of non-adherence. Nonadherence, short-term as well as long-term, could be prevented by applying the right educational approach during the consultation [22]. Therefore, patient education skills training is badly needed.

To meet this demand, Sluijs [23] has written a manual for physiotherapists to help them improve their educational skills. Her manual describes 11 strategies for improving the effectiveness of education, based on patients' adherence problems, the educational problems reported by physiotherapists, and on theoretical insights. Moreover, a training program was set up to study the manual and to practice educational and communication skills [24].

The aim of this article is to evaluate the effectiveness of the training on five of the 11 strategies.

\subsection{Explanation of the strategies}

1.2 .

Follow a planned and systematic approach. In some research a sharp decrease has been observed in the number of instructions given across the therapy sessions, with a maximum number of instructions in the second session and only a few at the end [25 and 26]. In an earlier paper from the pre-training phase of this study, we explored the content and sequence of instructions given by the participating physiotherapists [27]. Most of the instructions were still given at the start of treatment and the number decreased towards the end. But from an educational point of view it is better to keep a constant flow of instructions to avoid overloading the patient [25]. This is part of the trained strategy, to spread instructions evenly over sessions, with a rehearsal in the last session, to make the patient ready to apply the learned skills in new situations.

A second strategy concerns the discussion of patients' (non-)adherence. The problem of ineffective education is closely related to the problem of non-adherence. Sluijs (et al.) noticed from analysing audiotapes that patients seldom reported adherence problems [28]. So it is not adherence per se which is the problem, but the fact that adherence problems remain hidden. Part of the training is to learn to inquire in a non-threatening way into patients (non)adherence.

A logical continuation of discussing non-adherence is to inquire into its causes and to resolve problems. This does not imply that the therapist solves the problem for the patient, but rather that he or she monitors the feasibility of instructions and adapts them, if necessary. Health professionals are often mistakenly of the opinion that they are aware of the cause of non-adherence [29].

Enhance patients' feeling of self-efficacy. When patients feel helpless about trying to change their behaviour, or influence their health, their motivation to adhere to instructions declines. These findings are in line with general research findings about non-adherence, predicted by such theoretical models as the health belief model [30], self-efficacy [31], and self-regulation theory [32]. Physiotherapists can increase patients' self-efficacy by setting realistic and attainable goals and providing feedback. 
A last important aspect of the training is to tailor the information to patients' needs and attune them to their individual situations [22]. Patients usually experience problems in carrying out prescribed instructions and exercises. Exercising requires time and can be painful. Perseverance is required and triggers or cues are needed to remind patients. These kinds of problems differ per patient. That is why many authors recommend tailoring exercises and advice as much as possible to patients' particular situations and to routines [33 and 34]. Unfortunately, no single specific strategy enhances adherence in all patients. Patient educators have the greatest influence on adherence when they provide specific suggestions that fit into a patient's life style. This applies not only to physical therapy, but also to medication [35] and diets [36]. The other strategies are briefly outlined in Table 1.

\section{[TABLE 1]}

Given these considerations, we assume that after the training:

1. instructions are spread more equally across the sessions,

2. therapists and patients talk more often about adherence problems,

3. therapists provide solutions for adherence problems more often,

4. patients are more convinced of the effectiveness of the instructions,

5. patient education is tailored more to patient's particular situation.

\section{METHODS}

\subsection{Design}

Nineteen physiotherapists participated in the study. They were trained to improve their communication skills and the transfer of adherence enhancing skills. Patient education, as they practiced it in the pre-training stage, was assessed by means of registration of each session of five to 10 patients by the physiotherapist and by patient questionnaire, administered at the start of therapy (T1), at the end of therapy (T2) and 6 months later (T3). After the training the same procedure was followed. This is the one-group pretest-post-test [37]. One-group refers to the physiotherapists since we have two groups of patients.

In the pre-training sample 130 patients (1142 sessions) were included (T1). The response to the second questionnaire was $46 \%$ and to the third $61 \%$. Some patients were reluctant to respond at $\mathrm{T} 2$, having recently provided the same information on $\mathrm{T} 1$.

In the post-training sample 88 patients have been included ( 775 sessions), $61 \%$ responded to the second questionnaire and $88 \%$ to the third.

\subsection{Patients}

In the Netherlands, the majority of patients visit small private practices [38]. Most people are treated in a series of therapy or treatment sessions which last for about half an hour [39 and 40$]$.

In order to assess patient education, as given by the physiotherapists in our study, we required them to include consecutive patients above 16 years with back pain, except those with a proven HNP, patients with malign disorders and pregnant patients. By limiting ourselves to back pain, we meant to create a homogeneous group for which exercise and hence patient education is highly relevant [6, 7, 8 and 9]. These inclusion criteria were the same for the pre-training and the post-training group. Data concerning the sex and average age of the patients is shown in Table 2, which also contains information about the treatment goals. 


\section{[TABLE 2]}

Seven different treatment goals were distinguished. Treatment was most often aimed at increasing the lumbar spine range of motion and pain reduction (see Table 2). On average, each treatment has three goals. There were no substantial differences between the two groups.

\subsection{Measurement instruments}

\subsubsection{Registration form}

The physiotherapists recorded the instructions given to their patients in each session by means of a registration form (discussed by Kerssens et al. [27]). In physical therapy, registration forms can be a reliable source of information [41 and 42]. The form contained 34 topics in four areas: instructions about pain management (8), taking care of the back when performing daily activities (14), doing exercises (9), and recommendations concerning general fitness (3). See Table 3. Furthermore, the registration form permitted the therapist 10 additional items. The list was developed in two stages. First, all available information used by physiotherapists in practice was explored. All kinds of unofficially published brochures and leaflets were investigated, supplemented by the overview of 70 Back School programs compiled by Knibbe et al. [43], as well as the book edited by Goëken [44] containing extensive descriptions of major back management programs. From these sources, a list was compiled of all kinds of advice given to back pain patients. This list was checked for completeness and condensed into major categories by the authors. This rough list was then piloted by four experienced physiotherapists, resulting in the final list.

\section{[TABLE 3]}

\subsubsection{Patient questionnaire}

Patients were asked to answer the same questionnaire on three separate occasions. The physiotherapist gave patients the first questionnaire after their first visit (T1). The second questionnaire was mailed to patients just after their last visit (T2), and the third, 6 months after the last visit (T3).

These questionnaires contained, among others, questions about instructions, given by therapists, and their perceived effectiveness, possible discussion of (non-)adherence, and solutions offered by therapists. All questions had a precoded format, e.g. did you succeed in doing exercises the last 7 days? (no/1 day/2 days/... etc.); did it cause you any trouble? (no, yes, yes a lot!); did you tell your therapists? (yes/no), etc.

\subsection{Training description}

Communication skill training consisted of learning to clarify patients' perceptions, motives, and resistance. All the physiotherapists brought in a case study from their own practice. These cases were mostly patients with somatic complaints and considerable psycho-social problems. Adherence enhancing skills consisted of the application of various strategies. Five strategies have already been discussed. The training was based on a manual which describes 11 strategies to enhance adherence [23]. At the end of the course, participants rated the degree to which they had learned to apply these 11 enhancing strategies (see Table 1).

The therapists were trained by two experienced trainers (psychotherapists). The training involved seven training sessions, each of $4 \mathrm{~h}$ duration.

\subsection{Statistical analysis}


Sessions are nested in patients, and patients are sampled within a physiotherapist [45]. The data have therefore been analysed by means of a special form of linear regression analysis: Hierarchical Linear Modelling [46 and 47]. So we have information at three levels: sessions, patients, and physiotherapists. The data are therefore not from independent observations, violating a major assumption of traditional linear regression [48]. In Hierarchical Linear Modelling this factor is taken into account. In health services research, HLM has been applied in several projects [49, 50, 51 and 52]. Data analysis was carried out by means of the MLN software [53]. This multi-level approach implies that we cannot speak of one unit of analysis. On the contrary, we have tried to combine information from three units of analysis: the session, the patient and the therapist.

\section{RESULTS}

\subsection{Back care instructions}

Table 3 describes the instructions given to patients. Six thousand and eight topics have been discussed in 1142 available sessions in the pre-training phase, and 3518 topics in 775 sessions in the post-training phase.

In the pre-training phase, the mean number of instructions was 46 per patient and 5.3 per session. Of course, these are not all different kinds of instructions. Important information is often repeated in subsequent sessions. On average, patients receive instructions on 16 different topics, so instructions were repeated three times. In the post-training phase, the mean number was 40 instructions per patient, 4.5 instructions per session, and 14 different instructions per patient.

In both the pre-training and post-training phase, most instructions were spent on back care in daily activities and exercises. About $15 \%$ concerned pain management and $8 \%$ general fitness.

What is the content of these instructions? Most frequently mentioned, brought forward in nearly half of all sessions, are instructions concerning mobility of the lumbar spine. Next come instructions on exercises for the abdominal muscles, about sitting and standing posture, alternating the body position and exercises for the dorsal muscles. In seventh place is the first pain management instruction, taking rest. Doing analgesic exercises, recognizing limitations of the back and slowing down complete the top 10 of instructions, given by physiotherapists during sessions of patients with low back pain.

\subsection{The number of instructions across the sessions}

The first research question is on the equal distribution of instructions across the sessions.

Table 4 contains the results of this analysis.

\section{[TABLE 4]}

\subsection{Trends of back care in ADL and general fitness}

The trend analysis above, with the total number of instructions, is an introduction to the estimation of another series of trends for two distinctive kinds of instructions: back care in daily life activities and recommendations for general fitness. These were selected because in the pre-training phase of the study they showed a downward trend, whereas instructions on pain management and exercises were already equally spread at that stage. The total number of instructions between the different areas differs greatly, as Table 3 has already shown. To overcome this problem of scale, the dependent variables were standardized to $z$-scores before modelling the independent variables. This facilitated comparison of the results of the analyses in Table 5a,b. 


\section{[TABLE 5]}

Table 5a refers to instructions on back care in activities of daily life. The trend effect of the pre-training phase is greater than that of the post-training phase $(-0.07$ versus -0.3$)$. In both phases a first and a last session effect is seen.

Recommendations to promote general fitness were the last of the instructions analysed (Table 5b). The trend coefficient of the pre-training phase is small, but negative. In the posttraining phase the trend is absent. In both phases there is neither a first session effect, nor a last one.

In both cases, patient education is more evenly distributed in the post-training phase than in the pre-training phase.

\subsection{Inquire into and discuss patients' (non)adherence}

Table 6 gives the results of the analyses of the inquiry into patients' problems. The table shows the percentage of patients who told their physiotherapists about their difficulties. The majority of patients experienced these difficulties both in the pre-training phase as well in the post-training phase (both phases $77 \%$, data not included in the table). In the pre-training phase the percentage of patients who informed their physiotherapist was $54 \%$ at the beginning of treatment (T1) and $92 \%$ at the end (T2). In the post-training phase more patients told their physiotherapists about their problems in the early stage of treatment $(67 \%$ at T1). However, the differences are not statistically significant.

\section{[TABLE 6]}

\subsection{Resolve the problems}

Table 6 also provides information about whether the physiotherapists were able to resolve the patients' problems. In a large majority of cases the physiotherapists were able to help their patients. As this was already the case before the training, the differences between the measurement moments and pre-training or post-training phase are small and not statistically significant.

\subsection{Enhance patients' feelings of self-efficacy}

The bottom of Table 6 contains the results regarding the perceived effectiveness of the instructions. The table displays the percentages of patients who evaluated the things they could do to protect their backs in the performance of daily activities as effectively as they could at present and in the future. Before the training, about half of the patients believed instructions to be effective at the start of the treatment, about $85 \%$ believed them to be effective at the end of the treatment. Also, about half of the patients believed in a future effectiveness at the start of treatment and two-thirds did so at the end. The training did not alter these proportions in any way.

\subsection{Tailor regimen to patients' particular situation}

To test whether or not the regimen is tailored to patients' particular situations after the training, we compare the variances between sessions, between patients and between therapists before and after the training. Adaptation of instructions to the particular needs of specific patients should be visible in the large variations between patients as compared to the variation between therapists.

In Table 4 (estimates for all kinds of instructions together), we see, regarding the pretraining, in the bottom row that the largest variance component (5.07) is between the sessions. In fact, it is 56\% (5.07/9.08). The variance between patients (1.00) is less: $11 \%$ (1.00/9.08) of the total. This means that different patients receive information in different amounts. In other words, one patient's instructional input differs from another's. However, the variance between physiotherapists is much larger: $33 \%(3.01 / 9.08)$ of the total variance is 
at the physiotherapist level. So one physiotherapist is inclined to discuss more topics than another, irrespective of the patient, and there are considerable differences between therapists in this respect. In the post-training phase the figures are all of the same magnitude. The training did not change the figures in this respect.

\section{DisCUSSION}

Patient education, giving instructions and information on health behaviour, is core business for physiotherapists. In each session with low back pain patients these activities play a part. In this paper we investigated the dosage of educational activities over different sessions during treatment and the way education tailored to individual characteristics of patients was taken into account. Especially the impact of a training program to enhance these aspects was the subject of our investigation.

After the training the physiotherapists who participated in our study spread their patient education and instruction more equally across the different sessions in which they treated their patients. There were fewer instructions, avoiding instructional overload. The last session was utilized better after the training to recap the main points of instruction.

Our other anticipations were not confirmed. In the post-training phase, therapists and patients did not talk more often about adherence problems. Physiotherapists did not provide solutions for adherence problems more often. As a matter of fact, in the pre-training phase of our study physiotherapists already offered solutions to $90 \%$ of the patients with whom problems were discussed, so this aspect was at an optimum before the training and could not be further improved. We found little evidence that patients were more convinced of the effectiveness of the instructions in the post-training phase. Physiotherapists, at last, appeared to use identical approaches for different patients, as far as the amount of instructions is concerned. In summary, the training program did not succeed in teaching therapists a more individually oriented approach, which was considered beforehand a necessary condition to promote patients' adherence to instructions and self-efficacy in the future.

We could only investigate five of the 11 strategies on which the training was focused. Part of the original research plan was aimed at analysing audiotapes of the last therapy session. However, because of budgetary reasons of the Prevention Fund, we had to refrain from analysing these collected audiotapes. Therefore, only strategies that would have an impact in the registration form or the questionnaire could be tested. Registration as a means of evaluation has its limitations. When educational activities have been assessed by means of audiotapes, the resulting numbers are larger than in registration projects [9 and 10]. It appears that therapists register less than they are actually doing. However, this is a drawback that is equal for all participating therapists, in pre-test and post-test. Furthermore, registration automatically means a restriction to the quantitative approaches we used in our analyses. A more in-depth qualitative analysis is not possible.

From the training's evaluation we have learned that not all strategies had an equal impact on the trainees. Participants rated that they had learned little about the strategy to follow a planned and systematic approach, about the teaching of using cues, triggers and reminders, about the teaching to generalise advice to future situations and about a multi-disciplinary approach to support adherence. From the training's evaluation it appeared that not all the different adherence enhancing strategies were fully taught. The two (experienced) trainers held the opinion that seven sessions were not enough for this rather complex subject matter. More time to practice all the strategies was needed to be able to incorporate them into the therapist's daily routine. However, in the literature concerning the training of communication skills, most training with a duration comparable to ours report some effects.

Before the training started, the participants were asked to what extent they commanded the 11 different strategies. Much to our surprise, they rated their capacities as good, except for three strategies: following a planned and systematic approach, teach patients to use cues, triggers or reminders and inquire into the cause of adherence problems and resolve them. 
Discussion of problems and their possible resolutions appeared to be common practice already before the training, according to the patient's statements. So perhaps the selection of therapists has resulted in a group of practitioners with above average patient education skills. Another possibility is that our quantitative measurements are too superficial to catch the issues that are really of importance. Anyway, given the evidence presented, our conclusion is that the training induced less change than was anticipated.

An interesting result is the shift in pain management instructions. In the pre-training phase the most frequently given instruction was taking rest to avoid pain. The second most frequent was to do analgesic exercises. In the post-training phase of our study the frequency of these instructions were turned around. In the treatment of low back pain: "the era of routine radiography, strict bed rests, corsets and traction has passed and has been displaced by parsimonious imaging, early return to normal activities" [54] and greater emphasis on exercise to prevent recurrence or to treat chronic pain [55]. According to our results, these items are quickly incorporated in a physiotherapist's checklist. Clinical practical guidelines on acute low back problems not only stress structured patient education to enhance the performance of daily activities, but also recommend a large variety of exercises in order to return patients to the highest level of functioning [56]. Similar guidelines can be found in other Western countries, such as the United Kingdom [57] and the Netherlands [58]. Individual differences among therapists were found for all areas of information, but mostly for the instructions on taking care of the back in daily activities. Some therapists offered a lot of advice, whereas others did not. This is in accordance with the findings of one of our earlier studies [9]. Evidently, physiotherapists have considerable flexibility when instructing their patients. However, it is not certain that this flexibility is desirable. The question is: do the instructions depend too much on physiotherapists' preferences? We have encountered many differences among therapists in the amount of information they provide. We did not fully investigate the tailoring of the instructions to patients' individual circumstances. The fact that one therapist gives fewer instructions than other colleagues does not necessarily mean that the patients' situations are not being taken into consideration. This is possible, irrespective of the amount of instruction. Nevertheless, the fact that the variation among therapists is greater than the variation among patients is an indication of sub-optimal education. The estimated trend lines for individual patients showed that they all ended up with a small number of instructions, no matter what amount of information was given at the start of treatment [27]. This is quite inefficient from an educational point of view. The major cause was the decreasing amount of information about taking care of the back in daily activities.

The most important thing that we learned from this study is the poor operationalisation of the concept tailor-made education/instruction in order to enhance patient's self-efficacy. This study was handicapped by this poor operationalisation in two respects. The training was not sufficiently aimed at the specific actions required for a tailor-made patient education, such as teaching to use cues and triggers, and teaching the patient to generalize. Our measurement instruments were not sufficiently equipped to measure these outcomes in a satisfactory way.

\section{ACKNOWLEDGEMENTS}

This work was supported by grant No. 002822970 from the 'Preventiefonds' (Prevention Fund).

\section{REFERENCES}

1. M. van Tulder. Diagnostics and treatment of chronic low back pain in primary care, Thesis Publishers, Amsterdam (1996).

2. J. van der Velden, D.H. de Bakker, A.A.M.C. Claessens and F.G. Schellevis. Morbidity in general practice. Dutch national survey of general practice, Nivel, Utrecht (1992). 
3. J. Dekker and M.E. van Baar, Editors, Beleidsgericht evaluatie-en effectonderzoek extramurale fysiotherapie (Evaluation and effect study in physiotherapy for policy makers), Nivel, Utrecht (1995).

4. J.J. Kerssens and P.P. Groenewegen, Referrals to physiotherapy: the relation between the number of referrals, the indication for referral and the inclination to refer. Soc Sci Med 30 (1990), pp. 797-894.

5. A.M. Jette, K. Smith, S.M. Haley and K.D. Davis, Physiotherapy episodes of care for patients with low back pain. Phys Ther 74 (1994), pp. 101-115.

6. P. Wells and E. Lessard, Movement education and limitation of movement. In: P.D. Wall and R. Melzack, Editors, Textbook of pain (2nd ed.), Chruchill Livingstone, Edinburgh (1989), pp. 952-963.

7. B.W. Koes, W.J.J. Assendelft and G.J.M.G. van der Heijden, Physiotherapy exercises and back pain; a blinded review. Br Med J 302 (1991), pp. 1572-1576.

8. C. Yeh, M. Gonyea, J. Lemke and M. Volpe, Physiotherapy: evaluation and treatment of chronic pain. In: X. Aronoff, Editor, Evaluation and treatment of chronic pain, Urban \& Schwarzanberg, Baltimore (1985).

9. Sluijs EM. Patient education in physical therapy. Dissertation. Utrecht: Nivel, 1991.

10. J.E. Gahimer and E. Domholdt, Amount of patient education in physiotherapy practice and perceived effects. Phys Ther 76 (1996), pp. 1089-1096.

11. A.L. Nachemson, Exercise, fitness and back pain. In: C. Bouchard, R.J. Shepard, T. Stephens, J.R. Sutton and B.D. McPherson, Editors, Exercise, fitness and health, a consensus of current knowledge, Human Kinetic Books, Champaign, IL (1990).

12. E.E. Bartlett, At last, a definition (editorial). Patient Educ Couns 7 (1985), pp. 323-324.

13. A.M. Skelton, E.A. Murphy, R.J.L. Murphy and T.C. O'Dowd, Patient education for low back pain in general practice. Patient Educ Couns 25 (1995), pp. 329-334.

14. E.E. Bartlett, Forum: patient education. Eight principles from education research. Prev Med 14 (1985), p. 667.

15. B. Cook, M. Noteloviz, C. Rector and J.P. Krisher, An osteoporosis patient education and screening program: results and explanations. Patient Educ Couns 17 (1991), pp. 135-145.

16. B.J. Reeber, Evaluation the effects of a family education intervention. Rehabil Nurs 17 (1993), pp. 332-336.

17. E.M. Sluijs, J. van der Zee and G.J. Kok, Differences between physiotherapists in attention paid to patient education. Phys Theory Pract 9 (1993), pp. 103-107.

18. A. Morgan, Health teaching in clinical nursing practice. Aust J Adv Nurs 7 (1990), pp. 3640. 19. B.A. Stetson, J.W. Pichert, R.R. Roach, R.A. Lorenz, E.J. Boswell and D.G. Schlundt, Registered dietitians' teaching and adherence promotion skills during routine patient education. Patient Educ Couns 19 (1992), pp. 273-280.

20. E.M. Sluijs and E.B. Kuiper, Problemen die fysiotherapeuten ervaren bij het geven van voorlichting aan patiënten: een inventaisatie (Problems for physiotherapists with patient education). Ned Tijdschr Fysioth 100 (1990), pp. 128-132.

21. P.A. Lyne, The professions allied to medicine: their potential contribution to health education. Physiotherapy 72 (1986), pp. 10-12. | Cited By in Scopus (0)

22. E.M. Sluijs and J.J. Knibbe, Patient compliance with exercises: different theoretical approaches to short-term and long-term compliance. Patient Educ Couns 17 (1991), pp. 191-204.

23. E.M. Sluijs. Patiëntenvoorlichting door fysiotherapeuten; ontwikkeling van het observatieprotocol (Patient education by physiotherapists; development of observation protocol), Nivel, Utrecht (1988).

24. E.M. Sluijs, J.J. Kerssens and J. van der Zee, Adherence to physiotherapy. In: L. Myers and K. Midence, Editors, Adherence to medical treatment, Harwood Academic, Reading, UK (1998).

25. E.M. Sluijs, Patient education in physiotherapy: towards a planned approach. Physiotherapy 77 (1991), pp. 503-508.

26. Gahimer JE. Prevalence and effectiveness of patient education in physiotherapy practice. Dissertation. Indiana: Indiana University, 1995.

27. Kerssens JJ, Sluijs EM, Verhaak PFM, Knibbe JJ, Hermans IMJ. Back care instructions in physiotherapy: a trend analysis of individualized back care programs (in press). 
28. E.M. Sluijs, G.J. Kok and J. van der Zee, Correlates of exercise compliance in physiotherapy. Phys Ther 11 (1993), pp. 771-782.

29. E.E. Bartlett, J.C. Higginbotham, S. Cohen-Cole and J. Bird, How primary care residents manage patient non-adherence. Patient Educ Couns 16 (1990), pp. 53-60.

30. N.K. Janz and M.H. Becker, The health belief model: a decade later. Health Educ Q 11 (1984), pp. 1-47.

31. A. Bandura, Self-efficacy: toward an unifying theory of behaviour change. Psychol Rev 84 (1977), pp. 191-215. 32. H. Leventhal, R. Zimmerman and M. Gutmann, Compliance: a self-regulation perspective. In: W.D. Gentry, Editor, Handbook of behavioral medicine, The Guilford Press, New York (1984).

33. A. Craig Fisher, Adherence to sports injury rehabilitation programmes. Sports Med 73 (1990), pp. 151-158.

34. D. Meichenbaum and D.C. Turk. Facilitating treatment adherence: a practitioners guidebook, Plenum Press, New York (1987).

35. J.A. Cramer, Optimizing long term patient compliance. Neurology 45 (1995), pp. S25S28.

36. B.M. Wilson, Promoting compliance: the patient-provider partnership. Adv Ren Replace Ther 2 (1995), pp. 199-206.

37. T.D. Cook and D.T. Campbell. Quasi-experimentation. Design and analysis issues for field settings, Rand Mcnally College Publishing Company, Chicago (1979).

38. L. Hingstman and $\mathrm{H}$. Boon, Regional dispersion of independent professionals in primary health care in the Netherlands. Soc Sci Med 28 (1989), pp. 121-131.

39. J. Dekker, M.E. van Baar, E.Chr. Curfs and J.J. Kerssens, Diagnosis and treatment in physiotherapy: an investigation of their relationship. Phys Ther 73 (1993), pp. 568-580.

40. R.W.A. Valk, J. Dekker and M.E. van Baar, Physiotherapy for patients with back pain: a description. Physiotherapy 81 (1995), pp. 345-354.

41. E.F. van Triet, J. Dekker, J.J. Kerssens and E.Chr. Curfs, Reliability of the assessment of impairments and disabilities in survey research in the field of physiotherapy. Int Disabil Stud 12 (1990), pp. 61-65.

42. E.J.M. Hendriks, J.W. Brandsma, Y.F. Heerkens, R.A.B. Oostendorp and R.M. Nelson, Intraobserver and interobserver reliability of assesments of impairments and disabilities. Phys Ther 73 (1993), pp. 568-580.

43. J.J. Knibbe, N.E. Knibbe, J.W.H. Elvers, R.A.B. Oostendorp and H.W.A. Wams. Inventarisatie van rugscholen in Nederland (Overview of backschools in the Netherlands), Locomotion/SWSF, Amersfoort (1992).

44. L.N.H. Goëken, Editor, Rugscholen in Nederland (Backschools in the Netherlands), ISPO/LEMMA, Utrecht (1995).

45. L. Paterson and H. Goldstein, New statistical mehods for analysing social structures: an introduction to multilevel models. Br Educ Res J 17 (1991), pp. 387-393. 46. A.S. Bryk and S.W. Raudenbusch. Hierarchical linear models: applications and data management methods, Sage Publications, Newbury Park (1992).

47. H. Goldstein. Multilevel statistical models (2nd ed.), Halsted Press, New York (1995).

48. N. Draper and H. Smith. Applied regression analysis (2nd ed.), Wiley, New York (1981).

49. K. Jones and G. Moon, Multilevel assessment of immunisation uptake as a performance measuer in general practice. Br Med J 303 (1991), pp. 28-31. 50. J.M. Bensing, J.J. Kerssens and M. van der Pasch, Patient-directed gaze as a tool for discovering and handling psychosocial problems in general practice. J Nonverbal Behav 19 (1995), pp. 223-242.

51. J.J. Kerssens and E.M. van Yperen, Patients' evaluation of dietetic care: testing a cognitive attitude approach. Patient Educ Coun 27 (1996), pp. 217-226. 52. C. Duncan, K. Jones and G. Moon, Health related behavior in context: a multilevel modeling approach. Soc Sci Med 42 (1996), pp. 817-830.

53. J. Rasbash and G. Woodhouse. MLN command reference, Institute of Education, University of London, London (1995).

54. A. Malmivaara, U. Häkkinen, T. Aro et al., The treatment of acute low back pain-bed rest, exercises, or ordinary activity?. N Engl J Med 332 (1995), pp. 351-355.

55. R.A. Deyo, Acute low back pain: a new paradigma for management (editorial). Br Med J 313 (1996), pp. 1343-1344. 
Kerssens, J.J., Sluijs, E.M., Verhaak, P.F.M., Knibbe, H.J., Hermans, I.M.J. Educating patient educators: enhancing instructional effectiveness in physical therapy for low back pain patients. Patient Education and Counseling: 1999, 37(2), p. 165-176

56. J.M. Rothstein, A. Delitto and D.A. Scalzitti, Understanding AHCPR clinical paractical guideline No.14: acute, low back problems in adults. Pt Mag Phys Ther 3 (1995), pp. 1-24. 57. G. Waddel, G. Feder, A. McIntosch et al.. Low back pain evidence review, Royal College of General Practitioners, London (1996).

58. A. Faas, A.W. Chavannes, B.W. Koes et al., NHG-standaard lage rugpijn (NHG protocol low back pain). Huisarts Wet 39 (1996), pp. 18-31.

\section{TABLES}

Table 1

Number of physiotherapists $(N=19)$ reporting to have leamed either nothing, little or much about patient educational strategies

\begin{tabular}{lllc}
\hline & Nothing & Little & Much \\
\hline Follow a planned and systematic approach & 4 & 11 & 4 \\
Inquire into and discuss patients' (non-)adherence & 1 & 10 & 8 \\
Inquire into the cause of adherence problems & 1 & 12 & 6 \\
and resolve them & 1 & 12 & 6 \\
Enhance patients' feelings of self-efficacy/self esteem & 2 & 10 & 7 \\
Tailor regimen to patients' particular situation & 0 & 10 & 9 \\
Establish good rapport with patients & 1 & 13 & 5 \\
Acquire knowledge about patients' perceptions and self-care & 0 & 5 & 3 \\
Provide positive feedback for efforts about progress & 4 & 7 & 7 \\
Teach patient to use cues, triggers or reminders & 5 & 7 & 6 \\
Teach patient to translate and generalise advice & 4 & 9 & \\
Follow a multi-disciplinary approach to support adherence & & & 5 \\
\hline
\end{tabular}

Table 2

Description (mean or percentage) of patients and treatments

\begin{tabular}{llc}
\hline & Pre-training & Post-training \\
\hline$N$ & 130 & 88 \\
Men (\%) & 40.8 & 47.9 \\
Women (\%) & 59.2 & 52.1 \\
Age (years) & 42.8 & 46.7 \\
Duration at start of treatment (weeks) & 11.2 & 13.1 \\
Number of treatment goals (TGs) & 2.9 & 2.9 \\
TG, range of motion (\%) & 66.9 & 60.2 \\
TG, pain reduction (\%) & 50.8 & 64.4 \\
TG, posture improvement (\%) & 33.1 & 41.1 \\
TG, muscle strengthening (\%) & 29.7 & 39.7 \\
TG, ADL facilitation (\%) & 16.9 & 20.5 \\
TG, muscle tone regulation (\%) & 17.8 & 13.7 \\
TG, education in body mechanics (\%) & 11.9 & 4.1 \\
\hline
\end{tabular}


Kerssens, J.J., Sluijs, E.M., Verhaak, P.F.M., Knibbe, H.J., Hermans, I.M.J. Educating patient educators: enhancing instructional effectiveness in physical therapy for low back pain patients. Patient Education and Counseling: 1999, 37(2), p. 165-176

Table 3

Total percentages (of sessions) of information from 1142 sessions of 130 patients (pre-training) and 775 sessions of 88 patients from 19 physiotherapists (post-training)

\begin{tabular}{|c|c|}
\hline $\begin{array}{l}\text { Pre-training } \\
(\%)\end{array}$ & $\begin{array}{l}\text { Post-training } \\
(\%)\end{array}$ \\
\hline 23.4 & 14.9 \\
\hline 19.4 & 23.3 \\
\hline 11.9 & 11.3 \\
\hline 4.5 & 5.7 \\
\hline 3.6 & 3.8 \\
\hline 2.8 & 1.8 \\
\hline 2.5 & 4.6 \\
\hline 1.4 & 3.9 \\
\hline 7.0 & 2.3 \\
\hline 29.1 & 23.5 \\
\hline 27.2 & 25.8 \\
\hline 25.3 & 22.9 \\
\hline 24.6 & 18.9 \\
\hline 17.9 & 10.5 \\
\hline 17.4 & 17.9 \\
\hline 15.1 & 16.6 \\
\hline 9.1 & 4.9 \\
\hline 8.6 & 6.1 \\
\hline 7.1 & 7.2 \\
\hline 6.6 & 5.3 \\
\hline 3.4 & 1.0 \\
\hline 2.5 & 2.1 \\
\hline 2.3 & 1.0 \\
\hline 9.1 & 6.6 \\
\hline 48.7 & 43.4 \\
\hline 27.5 & 32.6 \\
\hline 21.9 & 25.8 \\
\hline 16.5 & 19.1 \\
\hline 12.9 & 16.1 \\
\hline 12.3 & 17.6 \\
\hline 9.6 & 8.6 \\
\hline 9.6 & 12.5 \\
\hline 8.0 & 5.4 \\
\hline 28.4 & 21.4 \\
\hline 10.8 & 6.4 \\
\hline 9.0 & 12.7 \\
\hline 8.7 & 8.6 \\
\hline 9.8 & 17.4 \\
\hline
\end{tabular}


Kerssens, J.J., Sluijs, E.M., Verhaak, P.F.M., Knibbe, H.J., Hermans, I.M.J. Educating patient educators: enhancing instructional effectiveness in physical therapy for low back pain patients.

Patient Education and Counseling: 1999, 37(2), p. 165-176

Table 4

Regression coefficients and (standard enors) of trend analysis (1142 sessions, 130 patients) (pre-training) and 775 sessions of 88 patients from 19 physiotherapists (post-training)

\begin{tabular}{|c|c|c|c|c|}
\hline \multirow{3}{*}{$\begin{array}{l}\text { Constant } \\
\text { Trend }\end{array}$} & \multicolumn{2}{|c|}{ Pre-training } & \multicolumn{2}{|c|}{ Post-training } \\
\hline & 6.35 & $(0.45)$ & 4.88 & $(0.60)$ \\
\hline & $-0.23^{*}$ & $(0.05)$ & -0.05 & $(0.03)$ \\
\hline First session & $0.88^{*}$ & $(0.28)$ & 0.49 & $(0.36)$ \\
\hline Last session & $0.94^{*}$ & $(0.24)$ & 1.69 & $(0.35)$ \\
\hline Importance of exercise in prevention & $0.77^{*}$ & $(0.18)$ & 0.42 & $(0.31)$ \\
\hline Variance between physiotherapists & $3.01^{*}$ & $(1.10)$ & $3.76^{\circ}$ & (1.72) \\
\hline Variance between patients & $1.00^{*}$ & $(0.24)$ & $0.81^{*}$ & $(0.30)$ \\
\hline Variance between sessions & $5.07^{*}$ & $(0.31)$ & $6.21^{*}$ & (1.37) \\
\hline Total variance & 9.08 & & 10.78 & \\
\hline
\end{tabular}

$$
{ }^{n} P<0.01 \text {. }
$$

Table 5

Regression coefficients and (standard enrors) of trend analyses for (a) back care in ADL and (b) general fitness"

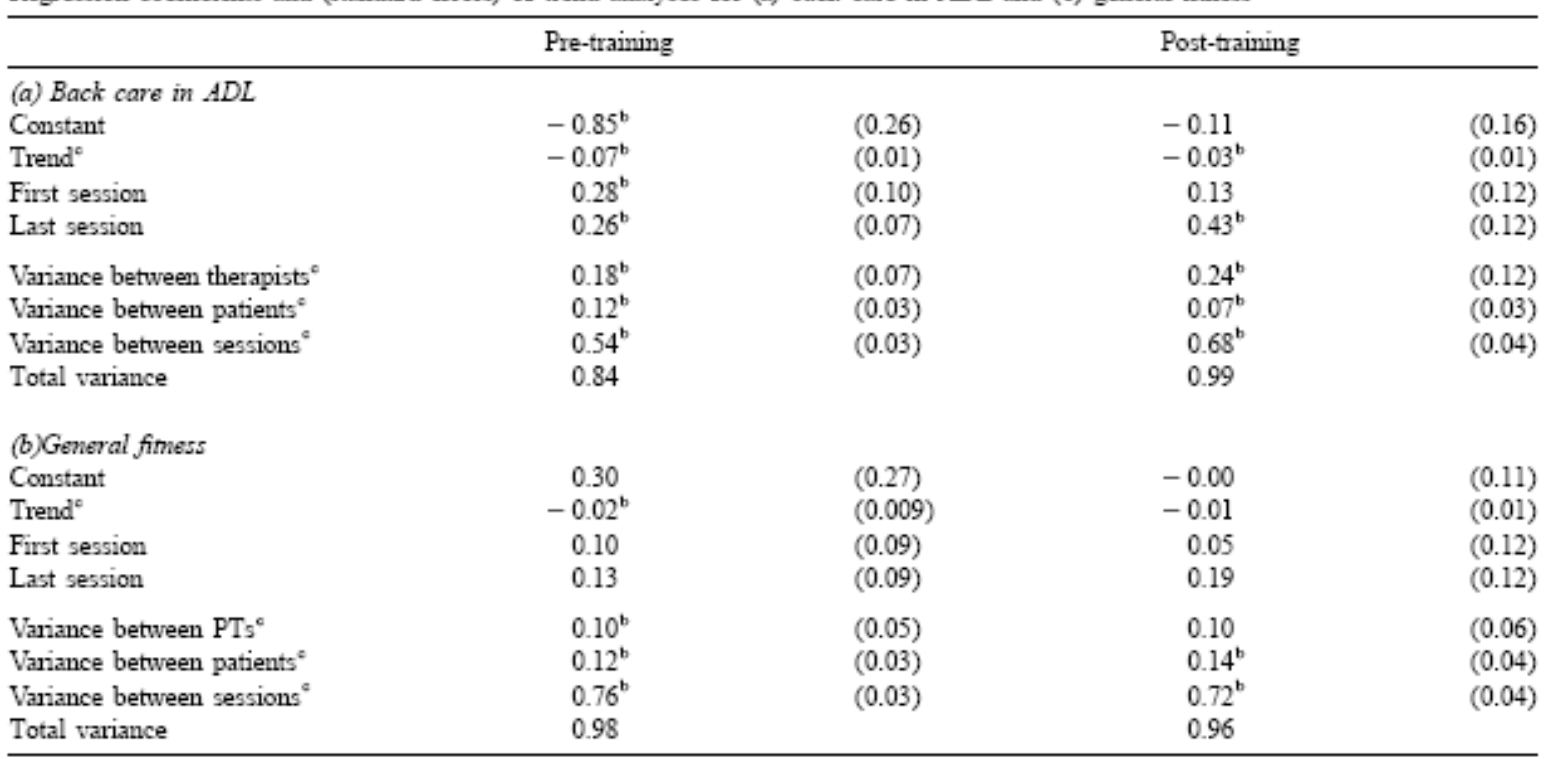

"Dependent variables are transformed to $z$-scores.

${ }^{b} P<0.05$

'For computational reasons the trend variable is centred around the sixth session. 
Kerssens, J.J., Sluijs, E.M., Verhaak, P.F.M., Knibbe, H.J., Hermans, I.M.J. Educating patient educators: enhancing instructional effectiveness in physical therapy for low back pain patients. Patient Education and Counseling: 1999, 37(2), p. 165-176

Table 6

Percentage of patients who discussed problems with their physiotherapist and percentage of patients whose therapist resolve their problems and percentage of patients who think that instructions are effective to prevent recurrence of their back pain-pre-training phase $(N=123)$ post-training phase $(N=82)^{3}$

\begin{tabular}{|c|c|c|}
\hline & $\begin{array}{l}\text { Pre-training } \\
(\%)\end{array}$ & $\begin{array}{l}\text { Post-training } \\
(\%)\end{array}$ \\
\hline \multicolumn{3}{|l|}{ Discussed problems } \\
\hline T1 & 62.2 & 70.3 \\
\hline $\mathrm{T} 2$ & 91.8 & 85.7 \\
\hline \multicolumn{3}{|l|}{ Resolved problems } \\
\hline $\mathrm{T} 1$ & 90.8 & 79.2 \\
\hline $\mathrm{T} 2$ & 90.6 & 96.7 \\
\hline \multicolumn{3}{|l|}{ Effective now } \\
\hline $\mathrm{T} 1$ & 57.6 & 59.6 \\
\hline $\mathrm{T} 2$ & 84.7 & 86.2 \\
\hline \multicolumn{3}{|l|}{ Effective in future } \\
\hline $\mathrm{T} 1$ & 45.8 & 66.0 \\
\hline $\mathrm{T} 2$ & 64.4 & 67.3 \\
\hline
\end{tabular}

"Differences between pre-training and post-training phase are not statistically significant. 